\title{
Putative functional non-coding polymorphisms in SELP significantly modulate sP-selectin levels, arterial stiffness and type 2 diabetes mellitus susceptibility
}

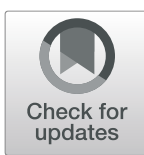

Raminderjit Kaur ${ }^{1,2}$, Jatinder Singh ${ }^{1}$, Rohit Kapoor ${ }^{3}$ and Manpreet Kaur ${ }^{1 *}$

\begin{abstract}
Background: P-selectin, encoded by SELP, has been implicated as an important molecule in the development of arterial stiffness, consequently leading to vascular complications in T2DM. SELP polymorphisms and increased levels of soluble P-selectin (SP-selectin) have been shown to be associated with several inflammatory diseases. The present work was designed to assess nine putative functional non-coding SELP variants in relation to SP-selectin levels and arterial stiffness in T2DM.

Methods: The genetic distribution of rs3917655, rs3917657, rs3917739, rs2235302, rs3917843 was determined by restriction fragment length polymorphism-polymerase chain reaction (RFLP-PCR). Genotyping of rs3917779 was performed by tetra primer amplification-refractory mutation system (ARMS)- PCR. Three SNPs i.e. rs3917853, rs3917854, rs3917855 were genotyped by Sanger sequencing. Construction of haplotypes was performed using PHASE software. The data thus obtained was analyzed by appropriate statistical tools.

Results: Two non-coding variants i.e. rs3917657 and rs3917854 of SELP were found to be associated with 2 and 1.7 -fold risk of disease development respectively. However, one non-coding variant rs2235302 was found to provide protection against disease development. Furthermore, variant allele of rs3917854 in T2DM patients was found to be associated with 2.07-fold very high vascular risk. Non-coding haplotype GCAGGCCGC was conferring 4.14-fold risk of disease development. Furthermore, overall sP-selectin levels were higher in T2DM patients when segregated according to genotypes as well as haplotypes. Significant genotype- phenotype correlation was observed for rs3917655 as well as rs3917739 variant in patients and for rs3917854 in controls. In vascular risk categories, a significant genotype- phenotype correlation was observed for rs3917655 and rs2235302. Furthermore, patients with CCGGGCCGC haplotype in high risk category were observed with higher levels of sP-selectin as compared to other haplotypes $(p<0.05)$.
\end{abstract}

Conclusions: Non-coding SELP variants may significantly modulate sP-selectin levels, vascular risk and T2DM susceptibility.

Keywords: Atherosclerosis, Haplotype, Pulse wave velocity, Selectin, SNP, Vascular risk

\footnotetext{
* Correspondence: dr.manpreetdhuna@gmail.com

${ }^{1}$ School of Medicine, Wayne State University, Detroit, Michigan, USA

Full list of author information is available at the end of the article
}

C C The Author(s). 2020 Open Access This article is licensed under a Creative Commons Attribution 4.0 International License, which permits use, sharing, adaptation, distribution and reproduction in any medium or format, as long as you give appropriate credit to the original author(s) and the source, provide a link to the Creative Commons licence, and indicate if changes were made. The images or other third party material in this article are included in the article's Creative Commons licence, unless indicated otherwise in a credit line to the material. If material is not included in the article's Creative Commons licence and your intended use is not permitted by statutory regulation or exceeds the permitted use, you will need to obtain permission directly from the copyright holder. To view a copy of this licence, visit http://creativecommons.org/licenses/by/4.0/ The Creative Commons Public Domain Dedication waiver (http://creativecommons.org/publicdomain/zero/1.0/) applies to the data made available in this article, unless otherwise stated in a credit line to the data. 


\section{Background}

Atherosclerosis is the major contributing factor for vascular complications, leading to high rate of mortality and morbidity in T2DM [1,2]. Atherosclerosis causes degeneration of arterial elasticity, resulting in arterial stiffness, which is a key risk factor for the development of nephropathy, myocardial infarction (MI), stroke and other vascular complications in T2DM patients [3-7]. In addition, advanced glycation end products (AGE) are also generated in an accelerated manner in diabetes as well as in pre-diabetes conditions $[8,9]$. AGE-RAGE (receptor of AGE) axis has been shown to modulate inflammatory cascade, contributing to cardiovascular damage in these conditions [10].

Pulse wave velocity (PWV), a non-invasive method, is widely used for the assessment of arterial stiffness [11]. Brachial-ankle PWV (baPWV) has been extensively used for the detection of augmented arterial stiffness in a large population and is suggested as an independent predictor of atherosclerotic vascular damage and cardiovascular risk [12-17]. Arterial stiffness is considered to be a low-grade inflammatory condition [18, 19]. Inflammatory response is characterized by translocation of the adhesion molecules, such as selectins to the surface, initiating the adhesion cascade for leukocyte recruitment to the vascular wall [20]. P-selectin, largest among the other selectins, is a key mediator of leukocyte, platelet and endothelium interactions. Binding of P-selectin to its ligands mediate initial steps of adhesion cascade i.e. tethering and rolling [21, 22]. This interaction further results into proteolytic shedding of P-selectin in circulation as soluble P-selectin (sP-selectin), which is documented as marker of endothelial dysfunction and platelet hyperactivity [23-27]. Furthermore, studies have suggested a significant association of raised sP-selectin levels with atherosclerotic vascular complications including coronary heart disease (CHD), CAD and MI in T2DM [26, 28-32].

SELP, a gene encoding P-selectin, variations have been suggested to contribute towards susceptibility to arterial stiffness and vascular complications. Furthermore, inactivation of SELP in atherosclerosis prone mouse models led to decreased formation of atherosclerotic plaques [33]. Several single-nucleotide polymorphisms (SNPs) of SELP have been shown to be associated with risk of different atherosclerotic as well as inflammatory diseases, including diabetic retinopathy, T2DM, CAD, $\mathrm{CHD}$, ischemic stroke and systemic lupus erythematous, peripheral artery disease in different populations [26, 34-42]. Furthermore, SELP variants were also reported to be associated with modulations in sP-selectin levels in different atherosclerotic vascular complications $[26,36$, 43-48]. Most of the available reports have evaluated the clinical relevance of only coding region variants of SELP.
The non-coding variants can also have detrimental effect on phenotypic expression of a gene. Only three noncoding SNPs of SELP i.e. rs3917657, rs2235302 and rs3917779, were previously found to be associated with systemic lupus erythematosus (SLE), carotid intimamedia thickness and diabetic retinopathy [48-51]. These variants may alter the gene expression by affecting transcription factor binding sites, splicing regulation and miRNA binding etc. [52].

Due to population-specific nature of association studies, there is a universal need to replicate the studies in different populations. So, the present study was designed to investigate role of non-coding SNPs as important genetic markers in T2DM. All the selected variants were documented to have putative functional role in our previous study [53]. As per literature survey, this is the first comprehensive study evaluating nine putative functional non-coding SELP variants in relation to sP-selectin levels, arterial stiffness and T2DM susceptibility.

\section{Methods \\ Study participants}

A total of 250 T2DM patients comprising 99 females and 152 males, with $\mathrm{HbA} 1 \mathrm{c} \geq 6.5 \%$, aged $30-80 \mathrm{y}$ and from Carewell Heart \& Superspeciality Hospital, Amritsar (PB), were enrolled for the present case-control study. HbA1c levels of patients were determined using fully automated Alere Afinion $^{\text {Tax }}$ analyzer by manufacturer's protocol (Afinion-AS100, Alera Technologies AS, Norway). Gender- and Age- matched 264 healthy controls (having fasting glucose $<100 \mathrm{mg} / \mathrm{dl}$ or HbA1c < 5.7\%) including 107 females and 157 males were also recruited from the adjoining areas. The details regarding demographic characteristics, disease history and arterial stiffness assessment as well as vascular risk stratification in T2DM patients has already been explained previously $[26,54]$. The blood samples were collected and processed for DNA and serum isolation [26].

\section{Genotyping of SELP variants}

A total of nine SNPs selected on the basis of in silico analyses were genotyped by various methods including RFLP-PCR, ARMS-PCR and Sanger sequencing. Genotyping of five variants i.e. rs3917655, rs3917657, rs3917739, rs3917843 and rs2235302, was performed using PCR-RFLP. Components and conditions used in PCR-RFLP of these SNPs are specified in Table 1. The details of various components used for restriction digestion reaction of the abovesaid variants are specified in supplementary table 1. Genotyping of rs3917779 was carried out using tetra primer ARMS-PCR. The primers used for tetra primer ARMS-PCR were $\mathrm{T}$ allele specific forward inner primer (GAATCTCAGGTAAGTCAC TTGTGAATTGAT); reverse outer primer (TTTCCT 
Table 1 Components and conditions used in PCR-RFLP of rs3917655, rs3917657, rs3917739, rs3917843 and rs223530

\begin{tabular}{|c|c|c|c|c|c|c|c|}
\hline \multirow[t]{3}{*}{ SNP } & \multirow[t]{3}{*}{ Primer sequence } & \multirow[t]{3}{*}{ PCR conditions } & \multirow{3}{*}{$\begin{array}{l}\text { Amplicone } \\
\text { Size (bp) }\end{array}$} & \multicolumn{4}{|l|}{ RFLP } \\
\hline & & & & \multirow[t]{2}{*}{$\begin{array}{l}\text { Restriction } \\
\text { enzymes }\end{array}$} & \multirow[t]{2}{*}{$\begin{array}{l}\text { Incubation } \\
\text { conditions }\end{array}$} & \multicolumn{2}{|c|}{$\begin{array}{l}\text { Product after } \\
\text { digestion (bp) }\end{array}$} \\
\hline & & & & & & Ancestral & Variant \\
\hline \multirow[t]{2}{*}{ rs3917655 } & \multirow{2}{*}{$\begin{array}{l}\text { 5'TGTCCACTTTGACCCTCCCA3' } \\
\text { 5'AGGGCAGAAAAGGAAACTATGTG3' }\end{array}$} & \multirow{2}{*}{$\begin{array}{l}\text { Initial denaturation at } 95^{\circ} \mathrm{C}(7 \mathrm{~min}) \\
30 \mathrm{~s} \text { at } 95^{\circ} \mathrm{C} \\
30 \mathrm{~s} \text { at } 58^{\circ} \mathrm{C} \\
30 \mathrm{~s} \text { at } 72^{\circ} \mathrm{C} \\
\text { Final elongation at } 72^{\circ} \mathrm{C} \text { for } 7 \mathrm{~min}\end{array}$} & \multirow[t]{2}{*}{405} & \multirow[t]{2}{*}{ Pvull } & \multirow[t]{2}{*}{ At $37^{\circ} \mathrm{C}$ for $2 \mathrm{~h}$} & 249 & \multirow[t]{2}{*}{405} \\
\hline & & & & & & 156 & \\
\hline \multirow[t]{2}{*}{ rs3917657 } & \multirow{2}{*}{$\begin{array}{l}\text { 5'ATCTTCTGGGACTGATCTGGA3' } \\
\text { 5'CCTGCCTGGTTCCTCCATAG3' }\end{array}$} & \multirow{2}{*}{$\begin{array}{l}\text { Initial denaturation at } 95^{\circ} \mathrm{C}(7 \mathrm{~min}) \\
30 \mathrm{~s} \text { at } 95^{\circ} \mathrm{C} \\
30 \mathrm{~s} \text { at } 60^{\circ} \mathrm{C} \\
30 \mathrm{~s} \text { at } 72^{\circ} \mathrm{C} \\
\text { Final elongation at } 72^{\circ} \mathrm{C} \text { for } 7 \mathrm{~min}\end{array}$} & \multirow[t]{2}{*}{516} & \multirow[t]{2}{*}{ Tfil } & \multirow[t]{2}{*}{ At $65^{\circ} \mathrm{C}$ for $2 \mathrm{~h}$} & 265 & 265 \\
\hline & & & & & & 251 & $\begin{array}{l}199 \\
52\end{array}$ \\
\hline \multirow[t]{2}{*}{ rs3917739 } & \multirow{2}{*}{$\begin{array}{l}\text { 5'AAAGCCCAGAGCAAAGAGGTAGT3' } \\
\text { 5'CCCTCCCTTCCCACCTTAACT3' }\end{array}$} & \multirow{2}{*}{$\begin{array}{l}\text { Initial denaturation at } 95^{\circ} \mathrm{C}(7 \mathrm{~min}) \\
30 \mathrm{~s} \text { at } 95^{\circ} \mathrm{C} \\
30 \mathrm{~s} \text { at } 60^{\circ} \mathrm{C} \\
30 \mathrm{~s} \text { at } 72^{\circ} \mathrm{C} \\
\text { Final elongation at } 72^{\circ} \mathrm{C} \text { for } 7 \mathrm{~min}\end{array}$} & \multirow[t]{2}{*}{546} & \multirow[t]{2}{*}{ Tfil } & \multirow[t]{2}{*}{ At $65^{\circ} \mathrm{C}$ for $2 \mathrm{~h}$} & \multirow[t]{2}{*}{546} & 328 \\
\hline & & & & & & & 218 \\
\hline \multirow[t]{2}{*}{ rs3917843 } & \multirow{2}{*}{$\begin{array}{l}\text { 5'ATTACATGCAATGCCTGCCT3' } \\
\text { 5'GGGGCATACTGTCCCTTITTGA3' }\end{array}$} & \multirow{2}{*}{$\begin{array}{l}\text { Initial denaturation at } 95^{\circ} \mathrm{C}(7 \mathrm{~min}) \\
30 \mathrm{~s} \text { at } 95^{\circ} \mathrm{C} \\
30 \mathrm{~s} \text { at } 59^{\circ} \mathrm{C} \\
30 \mathrm{~s} \text { at } 72^{\circ} \mathrm{C} \\
\text { Final elongation at } 72^{\circ} \mathrm{C} \text { for } 7 \mathrm{~min}\end{array}$} & \multirow[t]{2}{*}{578} & \multirow[t]{2}{*}{ BsaWl } & \multirow[t]{2}{*}{ At $60^{\circ} \mathrm{C}$ for $2 \mathrm{~h}$} & 329 & 578 \\
\hline & & & & & & 249 & \\
\hline \multirow[t]{2}{*}{ rs2235302 } & \multirow{2}{*}{$\begin{array}{l}\text { 5'GCCAACCTGTGAGGGTAGGAT3' } \\
\text { 5'ACCACTGTCCGCCTTATAAACT3' }\end{array}$} & \multirow{2}{*}{$\begin{array}{l}\text { Initial denaturation at } 95^{\circ} \mathrm{C}(7 \mathrm{~min}) \\
30 \mathrm{~s} \text { at } 95^{\circ} \mathrm{C} \\
30 \mathrm{~s} \text { at } 57^{\circ} \mathrm{C} \\
30 \mathrm{~s} \text { at } 72^{\circ} \mathrm{C} \\
\text { Final elongation at } 72^{\circ} \mathrm{C} \text { for } 7 \mathrm{~min}\end{array}$} & \multirow[t]{2}{*}{511} & \multirow[t]{2}{*}{ Ecil } & At $37^{\circ} \mathrm{C}$ for $2 \mathrm{~h}$ & 441 & 511 \\
\hline & & & & & & 70 & \\
\hline
\end{tabular}

PCR and digestion products were analyzed on 1.5 and $2.5 \%$ agarose gel pertained with EtBr, respectively

AATGGCACATGACTTGGAG); C allele specific reverse inner primer (GCTGCAATCTGTGGAGTGGA AAATAG) and forward outer primer (TCCACACAAA TGACCCTTAAGTTGG). The PCR conditions, including denaturation at $94{ }^{\circ} \mathrm{C}$ for $7 \mathrm{~min}$, followed by 35 cycles each of $30 \mathrm{~s}$ at $94{ }^{\circ} \mathrm{C}$ for denaturation, at $63^{\circ} \mathrm{C}$ for annealing, at $72{ }^{\circ} \mathrm{C}$ for extension and, a final extension step at $72{ }^{\circ} \mathrm{C}$ for $7 \mathrm{~min}$. The PCR products with expected size $441 \mathrm{bp}, 254 \mathrm{bp}$ ( $\mathrm{T}$ allele) and $243 \mathrm{bp}$ (C allele) were examined on $1.5 \%(\mathrm{w} / \mathrm{v})$ agarose gel pre-stained with ethidium bromide $(\mathrm{EtBr})$. The details of PCR components are specified in supplementary table 2 . The remaining three non-coding SNPs i.e., rs3917853, rs3917854, rs3917855 were genotyped using Sanger sequencing $(n=233)$. Due to paucity of funds, we were unable to perform sequencing of complete 514 subjects. The primers used for Sanger sequencing were forward primer (5'GCATTTGACCCGAGTCCTTA3') and reverse primer (5'AGGAAAAGGACAGGTCTCTGGA3'). The PCR conditions, including denaturation at $94^{\circ} \mathrm{C}$ for 7 min, followed by 35 cycles each of $30 \mathrm{~s}$ at $94{ }^{\circ} \mathrm{C}$ for denaturation, at $64^{\circ} \mathrm{C}$ for annealing, at $72{ }^{\circ} \mathrm{C}$ for extension and, a final extension step at $72^{\circ} \mathrm{C}$ for $7 \mathrm{~min}$. The PCR products with expected size $620 \mathrm{bp}$ were determined on $1.5 \%(\mathrm{w} / \mathrm{v})$ agarose gel pre-stained with EtBr. $10 \%$ of indicative samples of each SNP having various genotypes i.e., wild, variant and heterozygous were subjected to Sanger sequencing and concordance rate between genotyping by PCR-RFLP and sanger sequencing was $100 \%$.

\section{Evaluation of sP-selectin levels}

Serum sP-selectin levels were measured by ELISA, according to manufacturer's instructions (RayBiotech, USA) as discussed previously [26].

\section{Statistical analyses}

Sample size calculation was for genetic association was calculated using CaTS power calculator (http://csg.sph. umich.edu/abecasis/CaTS/) as explained in our previous report $[26,55]$. Comparison of genotypic and allelic frequencies between groups was carried out by Odds ratio using MedCalc software (https://www.medcalc.org/). Genetic models were determined by Web-Asso test program (http://www.asso-web.com/). Construction of haplotypes was carried out by PHASE software version 2.1.1 [56]. Linkage disequilibrium (LD) was determined by Haploview version 4.2 [57]. One-way ANOVA followed by Tukey's multiple comparison post hoc-test were used to compare sP-selectin levels (mean $\pm \mathrm{SD}$ ). Student's ttest was used to compare sP-selectin levels in different genotypic or haplotype combinations between the studied groups. Whole data was analyzed to remove the 
outliers using Box whisker plot. Various statistical analyses were carried out using SPSS version 16.0 (IL, USA and Chicago). For the whole analyses, $p$ value $<0.05$ was taken as statistically significant.

\section{Results}

Out of nine non-coding variants, two variants i.e. rs3917657 and rs3917854 were found to be associated with risk, while one variant rs2235302 showed protection towards disease development. The representative agarose gels showing PCR products and restriction digestion products as well as electropherograms of representative samples for all the studied variants are given in supplementary figure $1-7$. Due to low frequency $(n \leq 2)$ of homozygous variant and heterozygous genotypes of rs3917853 and rs3917855, these were excluded from further statistical analyses. Genotypic and allelic distribution was significant different for rs3917657 between patients and controls (Table 2). Heterozygosity and variant allele frequency were significantly more prevalent in patients with 1.9 -fold risk of T2DM. After adjustment for confounding factors of T2DM, the risk was marginally increased (Table 2). The association was indicated in dominant (CT/TT vs.CC; OR-1.98, 95\% CI-1.26-3.11, $p=0.003$ ) as well as co-dominant (TT/CT $=\mathrm{CT} / \mathrm{CC}$; OR-1.88, 95\% CI-1.24-2.85, $p=0.002$ ) models. For rs3917854, significantly high frequency of homozygous variant genotype was observed in patients, representing 2.4fold risk of disease development (Table 2), which was marginally increased after confounding factors adjustment (Table 2). The variant allele was found to confer 1.7 -fold risk of disease development. The association was indicated in co-dominant model $(\mathrm{AA} / \mathrm{GA}=\mathrm{GA} / \mathrm{GG} ; \quad$ OR-1.64, 95\% CI-1.12-2.41, $P$ 0.009). Genotypic and allelic distribution of rs2235302 was observed to be significantly different between patients and controls (Table 2). The frequency of homozygous variant genotype was significantly low in patients as compared to controls and was associated with protection. Marginally increased effect was observed after adjustment for confounding variables (Table 2). Similar heterozygosity distribution was obtained in both studied groups. The variant allele showed the protective association with disease development. There were suggestive evidences of an association of T2DM with co-dominant model (AA/GA = GA/GG; OR-0.75, 95\% CI-0.57-0.97, $p=0.034)$. High frequency of homozygous variant genotype as well as variant allele was observed for rs3917655 and rs3917739. However, the differences were not statistically significant. Similar genotypic as well as allelic frequency distribution was observed for rs3917843. In case of rs3917779, high prevalence of homozygous wild genotype was observed in both patients and controls. However, homozygous variant genotype was completely absent in both the studied groups.

To assess the effect of SELP variants on vascular risk, their frequency distribution was also compared between the vascular risk categories (Table 3). In variant rs3917657, rs3917843 and rs3917779, heterozygous variants and homozygous variants were combined to compute odds ratios as the frequency of homozygous variants is lesser i.e. $<5 \%$ in all the vascular risk categories. Out of all the variants, variant allele rs3917854 was found to be associated with 2-fold very high vascular risk, with significantly high frequency in very high risk (46.43\%) than high risk category (29.55\%). However, no significant difference in genotypic as well as allelic distribution was observed for other variants. Furthermore, these genotypic associations remained unaffected even after adjustment for various confounding factors of vascular risk (including age, gender, BMI, WHR, WSR, MAP, PP, LDL-C and VLDL) (data not shown).

For all the studied SNPs, deviation from Hardy-Weinberg was tested using Web-asso test. All genotypes were distributed according to HWE in controls (all $p$ values were more than 0.05 ). LD is generally determined by $\mathrm{D}^{\prime}$ value and LOD score. The D' value is ranged from 0 to1, where 0 designates complete equilibrium and 1 specifies complete LD. LOD represents $\log$ of the odds of there being LD between two loci and LOD score $\geq 2.0$ is normally considered as a significant evidence of LD. In the present study, three variants i.e. rs3917853, rs3917854, rs3917855 were excluded form LD analysis due to low statistical power. One SNP pair i.e. rs3917655/rs3917657 was observed with intermediate LD with D'/ LOD values 0.632/15.71 (Fig. 1). Three SNP pairs i.e. rs3917739/ rs3917657, rs3917655/rs2235302 and rs3917655/ rs3917739 were observed to have low LD with D'/ LOD values $0.511 / 2.6,0.430 / 9.81$ and $0.388 / 3.33$ respectively.

Haplotypes of SELP variants were constructed and their frequencies were compared in both the studied groups. The order of SNPs in the haplotypes was as follows: rs3917655, rs3917657, rs3917739, rs3917843, rs2235302, rs3917779, rs3917853, rs3917854, rs3917855. Out of 29 haplotypes, only 18 haplotypes with frequency $\geq 0.01$ in any of the studied group were subjected to further statistical analyses (Table 4). Being most prevalent in both the studied groups, CCAGGCCGC haplotype was taken as reference for further analysis. Three haplotypes i.e. CCAGGCCAC, GCAGGCCGC, GTAGACCGC were observed at higher frequencies (> $0.05)$ in patients than controls. Out of these, only GCAGGCCGC haplotype was observed to be associated with 4-fold risk. Although not statistically significant, 
Table 2 Genetic distribution of non-coding variants in patients and controls along with genetic models

\begin{tabular}{|c|c|c|c|c|c|c|c|c|c|}
\hline \multirow[t]{2}{*}{ Variants } & \multirow{2}{*}{$\begin{array}{l}\text { Patients } \\
\text { N (\%) }\end{array}$} & \multirow{2}{*}{$\begin{array}{l}\text { Controls } \\
\text { N (\%) }\end{array}$} & \multicolumn{2}{|l|}{ Crude } & \multicolumn{2}{|c|}{ Adjusted } & \multirow{2}{*}{$\begin{array}{l}\text { Dominant } \\
\text { Model } \\
\text { OR (95\% Cl) } \\
\boldsymbol{p} \text { value }\end{array}$} & \multirow{2}{*}{$\begin{array}{l}\text { Co- } \\
\text { dominant } \\
\text { Model } \\
\text { OR }(95 \% \text { Cl) } \\
\boldsymbol{p} \text { value }\end{array}$} & \multirow{2}{*}{$\begin{array}{l}\text { Recessive } \\
\text { Model } \\
\text { O R (95\% Cl) } \\
\boldsymbol{p} \text { value }\end{array}$} \\
\hline & & & OR $(95 \% \mathrm{Cl})$ & $\boldsymbol{p}$ value & $\mathrm{OR}$ & $\boldsymbol{p}$ value & & & \\
\hline \multicolumn{10}{|c|}{ rs3917655 Genotypes } \\
\hline $\mathrm{CC}$ & $132(52.8)$ & $149(56.44)$ & reference & & & & \multirow{3}{*}{$\begin{array}{l}1.16 \\
(0.82 \text { to } 1.64) \\
0.407\end{array}$} & \multirow{3}{*}{$\begin{array}{l}1.19 \\
(0.89 \text { to } 1.59) \\
0.235\end{array}$} & \multirow{3}{*}{$\begin{array}{l}1.68 \\
(0.77 \text { to } 3.66) \\
0.187\end{array}$} \\
\hline CG & $101(40.4)$ & $104(39.39)$ & 1.10 (0.76 to 1.57$)$ & 0.620 & 0.95 & 0.827 & & & \\
\hline GG & $17(6.8)$ & $11(4.17)$ & 1.74 (0.79 to 3.86$)$ & 0.170 & 1.70 & 0.259 & & & \\
\hline \multicolumn{10}{|l|}{ Alleles } \\
\hline $\mathrm{C}$ & $365(73)$ & $402(76.14)$ & reference & & & & & & \\
\hline G & $135(27)$ & $126(23.86)$ & 1.18 (0.89 to 1.56$)$ & 0.250 & & & & & \\
\hline \multicolumn{10}{|c|}{ rs3917657 Genotypes } \\
\hline $\mathrm{CC}$ & $189(75.6)$ & 227 (85.98) & reference & & & & \multirow{3}{*}{$\begin{array}{l}1.98 \\
(1.26 \text { to } 3.11) \\
0.003^{* *}\end{array}$} & \multirow{3}{*}{$\begin{array}{l}1.88 \\
(1.24 \text { to } 2.85) \\
0.002^{* *}\end{array}$} & \multirow{3}{*}{$\begin{array}{l}2.67 \\
(0.51 \text { to } 13.91) \\
0.218\end{array}$} \\
\hline $\mathrm{CT}$ & $56(22.4)$ & $35(13.25)$ & $1.92(1.20$ to 3.05$)$ & $0.005^{* *}$ & 1.94 & $0.014^{*}$ & & & \\
\hline $\mathrm{TT}$ & $5(2)$ & $2(0.7)$ & 3.00 (0.58 to 15.65$)$ & 0.191 & 3.16 & 0.214 & & & \\
\hline \multicolumn{10}{|l|}{ Alleles } \\
\hline $\mathrm{C}$ & $434(86.8)$ & 489 (92.61) & reference & & & & & & \\
\hline $\mathbf{T}$ & $66(26.4)$ & $39(14.77)$ & $1.91(1.26$ to 2.89$)$ & $0.002^{* *}$ & & & & & \\
\hline \multicolumn{10}{|c|}{ rs3917739 Genotypes } \\
\hline GG & $31(12.4)$ & $39(14.77)$ & reference & & & & \multirow{3}{*}{$\begin{array}{l}1.22 \\
(0.74 \text { to } 2.03) \\
0.433\end{array}$} & \multirow{3}{*}{$\begin{array}{l}1.21 \\
(0.94 \text { to } 1.56) \\
0.311\end{array}$} & \multirow{3}{*}{$\begin{array}{l}1.31 \\
(0.92 \text { to } 1.87) \\
0.135\end{array}$} \\
\hline GA & $111(44.4)$ & $128(48.48)$ & 1.09 (0.64 to 1.86$)$ & 0.750 & 1.24 & 0.483 & & & \\
\hline AA & $108(43.2)$ & $97(36.74)$ & $1.4(0.81$ to 2.41$)$ & 0.230 & 1.51 & 0.188 & & & \\
\hline \multicolumn{10}{|l|}{ Alleles } \\
\hline G & 173 (34.6) & 206 (39.01) & reference & & & & & & \\
\hline A & $327(65.4)$ & 322 (60.98) & 1.21 (0.94 to 1.56$)$ & 0.140 & & & & & \\
\hline rs39178 & Genotypes & & & & & & & & \\
\hline GG & $183(73.2)$ & $186(70.45)$ & reference & & & & & & \\
\hline $\mathrm{GA}$ & $62(24.8)$ & $72(27.27)$ & 0.87 (0.59 to 1.3 ) & 0.511 & 1.24 & 0.483 & $\begin{array}{l}\text { (0.59 to } 1.28) \\
0.489\end{array}$ & $\begin{array}{l}(0.63 \text { to } 1.25) \\
0.497\end{array}$ & $\begin{array}{l}(0.26 \text { to } 2.91) \\
0.831\end{array}$ \\
\hline AA & $5(2)$ & $6(2.27)$ & 0.85 (0.25 to 2.82 ) & 0.792 & 1.51 & 0.188 & & & \\
\hline Alleles & & & & & & & & & \\
\hline G & $428(81.06)$ & 444 (84.09) & reference & & & & & & \\
\hline A & $72(13.64)$ & $84(15.90)$ & 0.89 (0.63 to 1.25$)$ & 0.500 & & & & & \\
\hline rs22353 & Genotypes & & & & & & & & \\
\hline GG & 98 (39.2) & $86(32.57)$ & reference & & & & & & \\
\hline $\mathrm{GA}$ & $129(51.6)$ & 138 (52.27) & 0.82 (0.56 to 1.19 ) & 0.300 & 0.79 & 0.284 & $\begin{array}{l}(0.52 \text { to } 1.08) \\
0.125\end{array}$ & $\begin{array}{l}\text { (0.57 to } 0.98) \\
0.034^{*}\end{array}$ & $\begin{array}{l}\text { (0.34 to } 1.01) \\
0.049^{*}\end{array}$ \\
\hline$A A$ & $23(9.2)$ & $39(14.77)$ & 0.50 (0.28 to 0.91$)$ & $0.023^{*}$ & 0.54 & $0.046^{*}$ & & & \\
\hline Alleles & & & & & & & & & \\
\hline G & $325(65)$ & $310(58.71)$ & reference & & & & & & \\
\hline A & $175(35)$ & $218(41.29)$ & 0.76 (0.59 to 0.98$)$ & $0.038^{*}$ & & & & & \\
\hline rs39177 & Genotypes & & & & & & & & \\
\hline $\mathrm{CC}$ & $240(96)$ & 249 (94.32) & reference & & & & - & - & - \\
\hline $\mathrm{CT}$ & $10(4)$ & $15(5.68)$ & 0.69 (0.30 to 1.57$)$ & 0.380 & 0.492 & 0.134 & & & \\
\hline $\mathrm{TT}$ & - & - & - & & & & & & \\
\hline Alleles & & & & & & & & & \\
\hline C & $490(98)$ & $513(97.16)$ & reference & & & & & & \\
\hline
\end{tabular}


Table 2 Genetic distribution of non-coding variants in patients and controls along with genetic models (Continued)

\begin{tabular}{|c|c|c|c|c|c|c|c|c|c|}
\hline \multirow[t]{2}{*}{ Variants } & \multirow{2}{*}{$\begin{array}{l}\text { Patients } \\
\text { N (\%) }\end{array}$} & \multirow{2}{*}{$\begin{array}{l}\text { Controls } \\
\text { N (\%) }\end{array}$} & \multicolumn{2}{|l|}{ Crude } & \multicolumn{2}{|c|}{ Adjusted } & \multirow{2}{*}{$\begin{array}{l}\text { Dominant } \\
\text { Model } \\
\text { OR (95\% Cl) } \\
\boldsymbol{p} \text { value }\end{array}$} & \multirow{2}{*}{$\begin{array}{l}\text { Co- } \\
\text { dominant } \\
\text { Model } \\
\text { OR }(95 \% \text { Cl) } \\
\boldsymbol{p} \text { value }\end{array}$} & \multirow{2}{*}{$\begin{array}{l}\text { Recessive } \\
\text { Model } \\
\text { O R (95\% Cl) } \\
\boldsymbol{p} \text { value }\end{array}$} \\
\hline & & & OR $(95 \% \mathrm{Cl})$ & $\boldsymbol{p}$ value & $\mathrm{OR}$ & $\boldsymbol{p}$ value & & & \\
\hline $\mathbf{T}$ & $10(2)$ & $15(2.84)$ & $0.70(0.31$ to 1.57$)$ & 0.384 & & & & & \\
\hline \multicolumn{10}{|c|}{ rs3917854 Genotypes } \\
\hline GG & $50(42.73)$ & $66(56.89)$ & reference & & & & \multirow{3}{*}{$\begin{array}{l}1.77 \\
(1.05 \text { to } 0.97) \\
0.030^{*}\end{array}$} & \multirow{3}{*}{$\begin{array}{l}1.64 \\
(1.12 \text { to } 2.41) \\
0.009^{* *}\end{array}$} & \multirow{3}{*}{$\begin{array}{l}2.45 \\
(1.07 \text { to } 5.64) \\
0.027^{*}\end{array}$} \\
\hline GA & $47(40.17)$ & $41(36.20)$ & 1.51 (0.86 to 2.64$)$ & 0.140 & 1.32 & 0.386 & & & \\
\hline AA & $20(17.09)$ & $9(7.75)$ & 2.93 (1.23 to 6.98$)$ & $0.015^{*}$ & 2.96 & $0.030^{*}$ & & & \\
\hline \multicolumn{10}{|l|}{ Alleles } \\
\hline G & $147(62.82)$ & $173(74.56)$ & reference & & & & & & \\
\hline A & $87(37.17)$ & 59 (25.43) & $1.73(1.16$ to 2.58$)$ & $0.006^{* *}$ & & & & & \\
\hline
\end{tabular}

OR represents odds ratio, $C /$ represents confidence interval; ${ }^{*}$ represents $p$ value significant at 0.05 level; ${ }^{* *}$ represents $p$ value significant at 0.01 level

CCGGGCCGC, CCGGGCCAC, CCGGACCGC, GCAGACCGC haplotypes were less prevalent in patients $(p=0.05)$.

When segregated into vascular risk categories, nine haplotypes were observed with frequencies $\geq 0.01$ in any of the risk category. As CCAGGCCGC was the most prevalent $(>0.1)$ haplotype in two of the three categories, it was selected as the reference haplotype (data not shown). However, no statistically significant difference was found in vascular risk categories $(p>0.05)$. The other prevalent haplotypes in these risk categories were CCAGGCCAC (16\%; 12.5\%; 12.2\%), followed by CCGGGCCGC (14.3\%; 11.4\%; 7.7\%) and CCGGGCCAC (10.7\%; 5.6\%; 10\%).

In our previous study, patients showed significantly high sP-selectin levels as compared to controls ( $p<$ 0.001) [26]. For rs3917655, patients with heterozygous genotype were observed with significantly high sPselectin levels than patients with homozygous variant genotype $(p<0.05)$ (Fig. 2). Furthermore, patients with homozygous wild and heterozygous genotypes had significantly high sP-selectin levels $(p<0.05 ;<0.001$ respectively) than controls with the respective genotypes. Only homozygous wild genotype accounted for significantly raised levels of sP-selectin $(p<0.001)$ in patients as compared to controls for rs3917657. Furthermore, in rs3917739, a significant difference was observed in sPselectin levels only within the patients, where heterozygous genotype was accounted for significantly high levels as compared to homozygous wild genotype $(p<0.01)$. Similar results were observed when heterozygous genotype of patients was compared with respective genotype of controls $(p<0.001)$. Furthermore, in case of rs3917843 and rs2235302, no significant difference was observed within the studied groups $(p<0.05)$. Patients with homozygous wild as well as heterozygous genotypes of rs3917843, all genotypes of rs2235302 and homozygous wild genotype of rs3917779 were found to have significantly high sP-selectin levels as compared to respective controls. For rs3917854, significantly high sP-selectin levels were observed in controls with heterozygous genotype than homozygous wild genotype. Patients with homozygous wild as well as variant genotypes were observed to have significantly high sPselectin levels as compared to respective controls $(p<0.001$; $<0.01$ respectively).

Comparison of sP-selectin levels within vascular risk categories revealed significant difference within moderate risk category for rs3917655 variant $(p<0.05)$ (Fig. 3). Comparison between categories revealed significant difference between homozygous wild genotypes in high risk and moderate risk category for rs3917655 ( $p<0.05)$, while same pattern was observed in GA genotype for rs2235302 $(p<0.001)$. Furthermore, no statistically significant difference was found in vascular risk categories for other studied variant $(p>0.05)$.

sP-selectin levels were also segregated according to haplotypes. Only haplotypes with number of participants more than or equal to five were involved in the present analyses. The criterion of $n \geq 5$ participants was fulfilled by 12 haplotypes in patients and 11 haplotypes in control with 10 common haplotypes (Fig. 4). Significant difference was observed in sP-selectin levels only within the patient group $(p>0.001)$. Patients with haplotype GCAAACCGC were obserevd to have significantly higher sP-selectin levels than patients with haplotype CCAGACCGC, CCAGGCCAC, CCAGGCCGC, CCGGACCAC, CTAGGCCGC, GCAGACCGC, GCAGGCCGC and GTAGACCGC $(p<0.05 ; 0.01$; < $0.05 ;<0.05 ;<0.01 ;<0.01 ;<0.01 ;<0.05 ;<0.01$, respectively). In addition, patients with CCGGGCCGC haplotype were found to have significantly raised levels of $\mathrm{sP}$ selectin as compared to patients with haplotype CCAGGCCAC and GCAGACCGC ( $p<0.05$ each). When $\mathrm{sP}$-selectin levels were compared between patients 
Table 3 Comparison of genotypic/ allelic distribution of non-coding SELP variants between vascular risk categories

\begin{tabular}{|c|c|c|c|c|c|c|c|c|c|}
\hline \multirow{2}{*}{$\begin{array}{l}\text { SELP } \\
\text { SNPS }\end{array}$} & \multirow{2}{*}{$\begin{array}{l}\text { Very high } \\
\text { risk } \\
\text { category } \\
\mathrm{N}(\%)\end{array}$} & \multirow{2}{*}{$\begin{array}{l}\text { High risk } \\
\text { category } \\
N(\%)\end{array}$} & \multirow{2}{*}{$\begin{array}{l}\text { Moderate } \\
\text { risk } \\
\text { category } \\
\mathrm{N}(\%)\end{array}$} & \multicolumn{3}{|l|}{ Odds ratio $(95 \% \mathrm{Cl})$} & \multicolumn{3}{|c|}{$\boldsymbol{p}$ value } \\
\hline & & & & $\begin{array}{l}\text { Very high risk vs. high } \\
\text { risk }\end{array}$ & $\begin{array}{l}\text { High risk vs. moderate } \\
\text { risk }\end{array}$ & $\begin{array}{l}\text { Very high risk vs. moderate } \\
\text { risk }\end{array}$ & $\overline{p^{a}}$ & $p^{\mathbf{b}}$ & $p^{c}$ \\
\hline \multicolumn{10}{|c|}{ rs3917655 genotypes } \\
\hline GG & $30(55.55)$ & $56(51.37)$ & $46(53.48)$ & 1 & 1 & 1 & & & \\
\hline $\mathrm{GA}$ & $20(37.03)$ & $46(42.20)$ & $34(39.53)$ & $0.81(0.40$ to 1.61$)$ & 1.11 (0.61 to 2.00 ) & 0.90 (0.44 to 1.85$)$ & 0.550 & 0.720 & 0.771 \\
\hline AA & $4(7.40)$ & $7(6.42)$ & $6(6.97)$ & 1.07 (0.29 to 3.93$)$ & 0.96 (0.30 to 3.05) & 1.02 (0.26 to 3.93$)$ & 0.920 & 0.940 & 0.970 \\
\hline \multicolumn{10}{|l|}{ Alleles } \\
\hline G & $80(74.07)$ & $\begin{array}{l}158 \\
(72.47)\end{array}$ & $\begin{array}{l}126 \\
(73.25)\end{array}$ & 1 & 1 & 1 & & & \\
\hline A & $28(25.93)$ & $60(27.53)$ & $46(26.75)$ & 0.92 (0.54 to 1.55$)$ & 1.04 (0.66 to 1.63$)$ & $0.96(0.55$ to 1.65$)$ & 0.750 & 0.860 & 0.870 \\
\hline \multicolumn{10}{|c|}{ rs3917657 genotypes } \\
\hline $\mathrm{CC}$ & 38 (70.37) & $81(74.31)$ & $69(80.23)$ & 1 & 1 & 1 & & & \\
\hline $\mathrm{CT}$ & $15(27.77)$ & $26(23.8)$ & $15(17.44)$ & 1.23 (0.58 to 2.58$)$ & 1.47 (0.72 to 3.00$)$ & 1.81 (0.80 to 4.11$)$ & 0.581 & 0.282 & 0.150 \\
\hline$C T+T$ & $16(29.62)$ & $28(26.16)$ & $17(19.76)$ & 1.22 (0.59 to 2.51$)$ & 1.40 (0.71 to 2.77$)$ & 1.71 (0.78 to 3.76$)$ & 0.593 & 0.331 & 0.183 \\
\hline \multicolumn{10}{|l|}{ Alleles } \\
\hline C & $91(84.25)$ & $\begin{array}{l}188 \\
(86.23)\end{array}$ & $\begin{array}{l}153 \\
(88.95)\end{array}$ & 1 & 1 & 1 & & & \\
\hline $\mathbf{T}$ & $17(15.75)$ & $30(13.77)$ & $19(11.05)$ & 1.17 (0.61 to 2.23 ) & 1.28 (0.69 to 2.37 ) & 1.50 (0.74 to 3.04$)$ & 0.630 & 0.420 & 0.250 \\
\hline \multicolumn{10}{|c|}{ rs3917739 genotypes } \\
\hline GG & $6(11.11)$ & $11(10.09)$ & $14(16.27)$ & 1 & 1 & 1 & & & \\
\hline GA & $28(51.85)$ & $52(47.70)$ & $31(36.04)$ & 0.99 (0.33 to 2.95 ) & 2.13 (0.86 to 5.28$)$ & 2.11 (0.71 to 6.23 ) & 0.980 & 0.101 & 0.171 \\
\hline$A A$ & $20(37.03)$ & $46(42.20)$ & $41(47.67)$ & 0.79 (0.26 to 2.45$)$ & 1.43 (0.58 to 3.49 ) & 1.14 (0.38 to 3.40$)$ & 0.690 & 0.432 & 0.810 \\
\hline \multicolumn{10}{|l|}{ Alleles } \\
\hline G & $40(37.03)$ & 74 (33.94) & $59(34.30)$ & 1 & 1 & 1 & & & \\
\hline A & $68(62.97)$ & $\begin{array}{l}144 \\
(66.06)\end{array}$ & $113(65.7)$ & 0.87 (0.54 to 1.41$)$ & 1.02 (0.66 to 1.54$)$ & 0.89 (0.54 to 1.46$)$ & 0.581 & 0.940 & 0.643 \\
\hline \multicolumn{10}{|c|}{ rs3917843 genotypes } \\
\hline GG & $35(64.81)$ & $81(74.31)$ & $66(76.74)$ & 1 & 1 & 1 & & & \\
\hline GA & 19 (35.18) & $24(22.01)$ & 19 (22.09) & 1.83 (0.89 to 3.76$)$ & 0.97 (0.49 to 1.92) & 1.88 (0.88to 4.01) & 0.099 & 0.934 & 0.100 \\
\hline $\begin{array}{l}\mathrm{GA}+ \\
\mathrm{AA}\end{array}$ & 19 (35.18) & $28(26.16)$ & $20(23.25)$ & 1.57 (0.78 to 3.17$)$ & 1.14 (0.59 to 2.20$)$ & 1.79 (0.84 to 3.79$)$ & 0.209 & 0.695 & 0.127 \\
\hline \multicolumn{10}{|l|}{ Alleles } \\
\hline G & $89(82.40)$ & $\begin{array}{l}186 \\
(85.32)\end{array}$ & $\begin{array}{l}151 \\
(87.79)\end{array}$ & 1 & 1 & 1 & & & \\
\hline A & 19 (17.6) & $32(14.68)$ & $21(12.21)$ & 1.24 (0.66 to 2.31$)$ & 1.23 (0.68 to 2.23 ) & 1.53 (0.78 to 3.01$)$ & 0.496 & 0.480 & 0.212 \\
\hline \multicolumn{10}{|c|}{ rs2235302 genotypes } \\
\hline GG & $21(38.88)$ & $42(38.53)$ & $35(40.69)$ & 1 & 1 & 1 & & & \\
\hline GA & $31(57.40)$ & $55(50.45)$ & $42(48.83)$ & 1.13 (0.57 to 2.23$)$ & 1.09 (0.59 to 1.99$)$ & 1.23 (0.60 to 2.50$)$ & 0.730 & 0.770 & 0.561 \\
\hline AA & $2(3.70)$ & $12(11.00)$ & $9(10.46)$ & 0.33 (0.07 to 1.63$)$ & 1.11 (0.42 to 2.94) & 0.37 (0.07 to 1.88$)$ & 0.171 & 0.832 & 0.230 \\
\hline \multicolumn{10}{|l|}{ Alleles } \\
\hline G & $73(67.59)$ & $\begin{array}{l}139 \\
(63.76)\end{array}$ & $\begin{array}{l}112 \\
(65.11)\end{array}$ & 1 & 1 & 1 & & & \\
\hline A & $35(32.41)$ & $79(36.24)$ & $60(34.89)$ & 0.84 (0.52 to 1.37$)$ & 1.06 (0.69 to 1.61$)$ & 0.89 (0.53 to 1.49$)$ & 0.490 & 0.783 & 0.673 \\
\hline \multicolumn{10}{|c|}{ rs3917779 genotypes } \\
\hline $\mathrm{CC}$ & $53(98.24)$ & $\begin{array}{l}107 \\
(98.15)\end{array}$ & $79(91.86)$ & 1 & 1 & 1 & & & \\
\hline CT & $1(1.76)$ & $2(1.85)$ & $7(8.14)$ & 1.00 (0.08 to 11.38$)$ & 0.21 (0.04 to 1.04$)$ & 4.70 (0.56 to 39.28$)$ & 0.620 & 0.056 & 0.150 \\
\hline
\end{tabular}


Table 3 Comparison of genotypic/ allelic distribution of non-coding SELP variants between vascular risk categories (Continued)

\begin{tabular}{|c|c|c|c|c|c|c|c|c|c|}
\hline \multirow{2}{*}{$\begin{array}{l}\text { SELP } \\
\text { SNPS }\end{array}$} & \multirow{2}{*}{$\begin{array}{l}\text { Very high } \\
\text { risk } \\
\text { category } \\
\text { N (\%) }\end{array}$} & \multirow{2}{*}{$\begin{array}{l}\text { High risk } \\
\text { category } \\
N(\%)\end{array}$} & \multirow{2}{*}{$\begin{array}{l}\text { Moderate } \\
\text { risk } \\
\text { category } \\
\mathrm{N}(\%)\end{array}$} & \multicolumn{3}{|l|}{ Odds ratio $(95 \% \mathrm{Cl})$} & \multicolumn{3}{|c|}{$\boldsymbol{p}$ value } \\
\hline & & & & $\begin{array}{l}\text { Very high risk vs. high } \\
\text { risk }\end{array}$ & $\begin{array}{l}\text { High risk vs. moderate } \\
\text { risk }\end{array}$ & $\begin{array}{l}\text { Very high risk vs. moderate } \\
\text { risk }\end{array}$ & $\overline{p^{a}}$ & $p^{\mathbf{b}}$ & $p^{c}$ \\
\hline$C T+\pi$ & $1(1.76)$ & $2(1.85)$ & $7(8.14)$ & $1.00(0.08$ to 11.38$)$ & 0.21 (0.04 to 1.04 ) & 4.70 (0.56 to 39.28$)$ & 0.620 & 0.056 & 0.150 \\
\hline \multicolumn{10}{|l|}{ Alleles } \\
\hline C & $\begin{array}{l}107 \\
(99.07)\end{array}$ & $\begin{array}{l}216 \\
(99.08)\end{array}$ & $\begin{array}{l}165 \\
(95.93)\end{array}$ & 1 & 1 & 1 & & & \\
\hline$T$ & $1(0.93)$ & $2(0.92)$ & $7(4.07)$ & 2.01 (0.12 to 32.44) & 0.21 (0.04 to 1.06 ) & 4.54 (0.55 to 37.42$)$ & 0.622 & 0.059 & 0.160 \\
\hline \multicolumn{10}{|c|}{ rs3917854 genotypes } \\
\hline GG & $8(28.57)$ & $23(52.27)$ & $19(42.22)$ & 1 & 1 & 1 & & & \\
\hline GA & $14(50)$ & $16(36.36)$ & $17(37.77)$ & 2.51 (0.86 to 7.39$)$ & 0.77 (0.312 to 1.94$)$ & 1.95 (0.66 to 5.80$)$ & 0.093 & 0.589 & 0.226 \\
\hline AA & $6(21.4)$ & $5(11.36)$ & $9(20)$ & 3.45 (0.82 to 14.47$)$ & 0.46 (0.13 to 1.60$)$ & 1.58 (0.42 to 5.94$)$ & 0.090 & 0.222 & 0.495 \\
\hline \multicolumn{10}{|l|}{ Alleles } \\
\hline G & $30(53.57)$ & $62(70.45)$ & $55(61.11)$ & 1 & 1 & 1 & & & \\
\hline A & $26(46.43)$ & $26(29.55)$ & 35 (38.89) & 2.07 (1.03 to 4.15$)$ & $0.66(0.35$ to 1.23$)$ & 1.36 (0.69 to 2.67$)$ & $0.041^{a}$ & & 0.369 \\
\hline
\end{tabular}

arepresents $p$ value significant at 0.05 level pa denotes for $p$ value of comparison between very high risk and high risk category; $\mathrm{p}^{\mathrm{b}}$ denotes for $p$ value of comparison between high risk and moderate risk category; $p^{c}$ denotes for $p$ value of comparison between very high risk and moderate risk category

and controls, patients with haplotype GCAAACCGC, CCAGGCCGC and CCGGGCCGC were observed with significantly high sP-selectin levels as compared to controls with respective haplotypes $(p<0.01 ;<0.05 ;<0.01$, respectively).

Segregation of sP-selectin levels according to haplotypes in various vascular risk categories is shown in Fig. 5. A total of 4 haplotypes in very high-risk category and 6 haplotypes each in both high risk and moderate risk category were fulfilled the criterion of participants more than and equal to 5 . sP-selectin levels were significantly different only within high risk category, where patients with CCGGGCCGC haplotypes were having significantly elevated sP-selectin levels in comparison to patients with CCAGGCCAC, CCAGGCCGC,
CCGGACCGC, CCGGACCAC and CTAGGCCGC haplotypes $(p<0.05$; $<0.01 ;<0.01 ;<0.05 ;<0.01$; $<0.01$, respectively). However, no significant difference in sPselectin levels was found for any of the haplotype when compared between the categories $(p>0.05)$.

\section{Discussion}

T2DM, also known as non-insulin-dependent diabetes or adult-onset diabetes, is accounting for $90-95 \%$ of total DM cases worldwide and is the most prevalent form of DM. Adverse effects of chronic hyperglycemia in T2DM are generally divided into microvascular and macrovascular complications. The micro-vascular complications comprised of diabetic retinopathy, neuropathy and nephropathy [58]. The macro-vascular

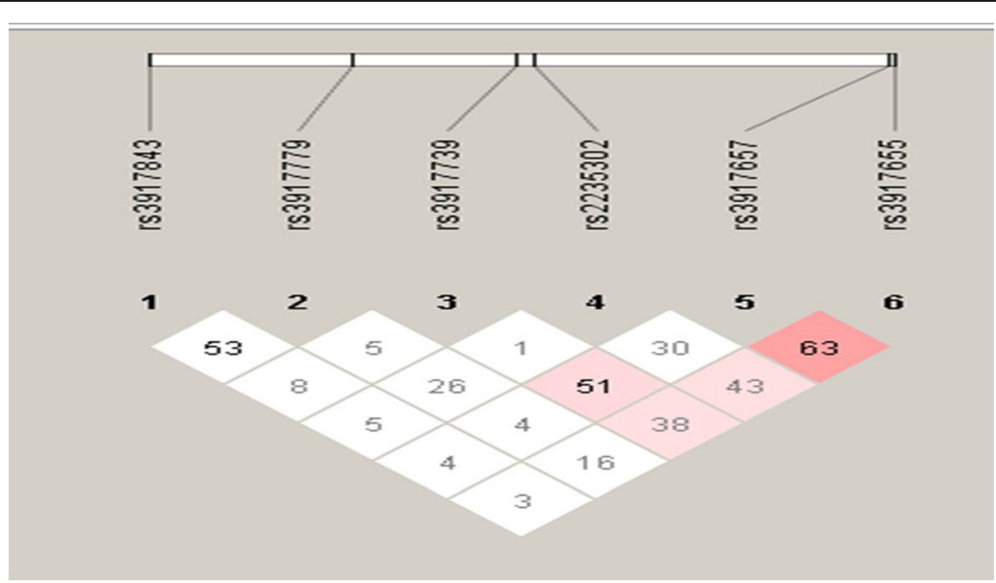

Fig. 1 LD plot of SELP variants. The dark pink squares represents intermediate $L D\left(D^{\prime}=0.632 ; L O D>2.00\right)$, light pink squares represents low $L D$ $\left(D^{\prime}=0.511,0.430\right.$ and $\left.0.388 ; L O D>2.00\right)$ and white/blue squares indicates non-significant $L D(L O D<2.00)$ 
Table 4 Comparison of non-coding haplotype distribution between patients and controls

\begin{tabular}{|c|c|c|c|c|c|c|c|}
\hline Haplotypes & $\begin{array}{l}\text { Patients } \\
(\mathrm{N})\end{array}$ & $\begin{array}{l}\text { Freq. } \\
(2 \boldsymbol{N}=234)\end{array}$ & $\begin{array}{l}\text { Controls } \\
(\mathrm{N})\end{array}$ & $\begin{array}{l}\text { Freq. } \\
(2 \boldsymbol{N}=232)\end{array}$ & OR & $95 \% \mathrm{Cl}$ & $\boldsymbol{p}$ value \\
\hline CCAGGCCGC & 38 & 0.1623 & 45 & 0.1939 & 1 & 1 & \\
\hline CCAGGCCAC & 31 & 0.1324 & 21 & 0.0905 & 1.74 & 0.86 to 3.53 & 0.119 \\
\hline CCGGGCCGC & 20 & 0.0854 & 39 & 0.1681 & 0.61 & 0.30 to 1.21 & 0.157 \\
\hline CCGGGCCAC & 18 & 0.0769 & 19 & 0.0818 & 1.13 & 0.52 to 2.43 & 0.771 \\
\hline GCAGGCCGC & 14 & 0.0598 & 4 & 0.0172 & 4.14 & 1.25 to 13.65 & $0.019^{a}$ \\
\hline GTAGACCGC & 14 & 0.0598 & 6 & 0.0258 & 2.76 & 0.96 to 7.89 & 0.057 \\
\hline CCGGACCGC & 11 & 0.0470 & 15 & 0.0646 & 0.86 & 0.35 to 2.11 & 0.756 \\
\hline CCGGACCAC & 9 & 0.0384 & 8 & 0.0344 & 1.33 & 0.46 to 3.79 & 0.590 \\
\hline CCAGACCGC & 9 & 0.0384 & 5 & 0.0215 & 2.13 & 0.65 to 6.90 & 0.206 \\
\hline CTAGGCCGC & 7 & 0.0299 & 2 & 0.0086 & 4.14 & 0.81 to 21.14 & 0.087 \\
\hline GCAGACCGC & 7 & 0.0299 & 19 & 0.0818 & 0.43 & 0.16 to 1.14 & 0.093 \\
\hline CCGAGCCGC & 6 & 0.0256 & 4 & 0.0172 & 1.77 & 0.46 to 6.76 & 0.399 \\
\hline GCAAACCGC & 6 & 0.0256 & 8 & 0.0344 & 0.88 & 0.28 to 2.78 & 0.838 \\
\hline CCGAGCCAC & 4 & 0.0170 & 2 & 0.0086 & 2.36 & 0.41 to 13.64 & 0.334 \\
\hline CCAAACCGC & 3 & 0.0128 & 2 & 0.0086 & 1.77 & 0.28 to 11.19 & 0.540 \\
\hline GCGGACCGC & 3 & 0.0128 & 3 & 0.0129 & 1.18 & 0.22 to 6.21 & 0.841 \\
\hline CCAAGCCGC & 2 & 0.0085 & 4 & 0.0172 & 0.59 & 0.10 to 3.41 & 0.557 \\
\hline GCAGGTCGC & 1 & 0.0042 & 3 & 0.0129 & 0.39 & 0.03 to 3.95 & 0.429 \\
\hline
\end{tabular}

OR denotes for odds ratio, $\mathrm{Cl}$ denotes for confidence interval; ${ }^{a}$ represents statistical significance at 0.05 level, Freq. denotes for frequency, $N$ denotes for number

complications are exhibited as accelerated atherosclerosis that results into premature coronary artery disease (CAD), severe peripheral vascular disease and increased risk of cerebrovascular diseases [59-62]. P-selectin, Ctype lectin, is known as one of the key markers of platelet activation and endothelial dysfunction. Because of the involvement of initial steps of leukocyte recruitment and thrombus formation, P-selectin has been suggested to play an important role in progression of atherothrombosis, thereby increasing risk of atherosclerotic vascular complications [63, 64]. SELP variants have been suggested as modulators in various inflammatory and atherothrombotic diseases $[26,34-36,38-41]$. Moreover, various SELP variants have been reported to influence the levels of soluble P-selectin in different atherosclerotic vascular complications [26, 36, 43-48]. Since the previous studies were mostly focused on missense mutations, the present study employed case-

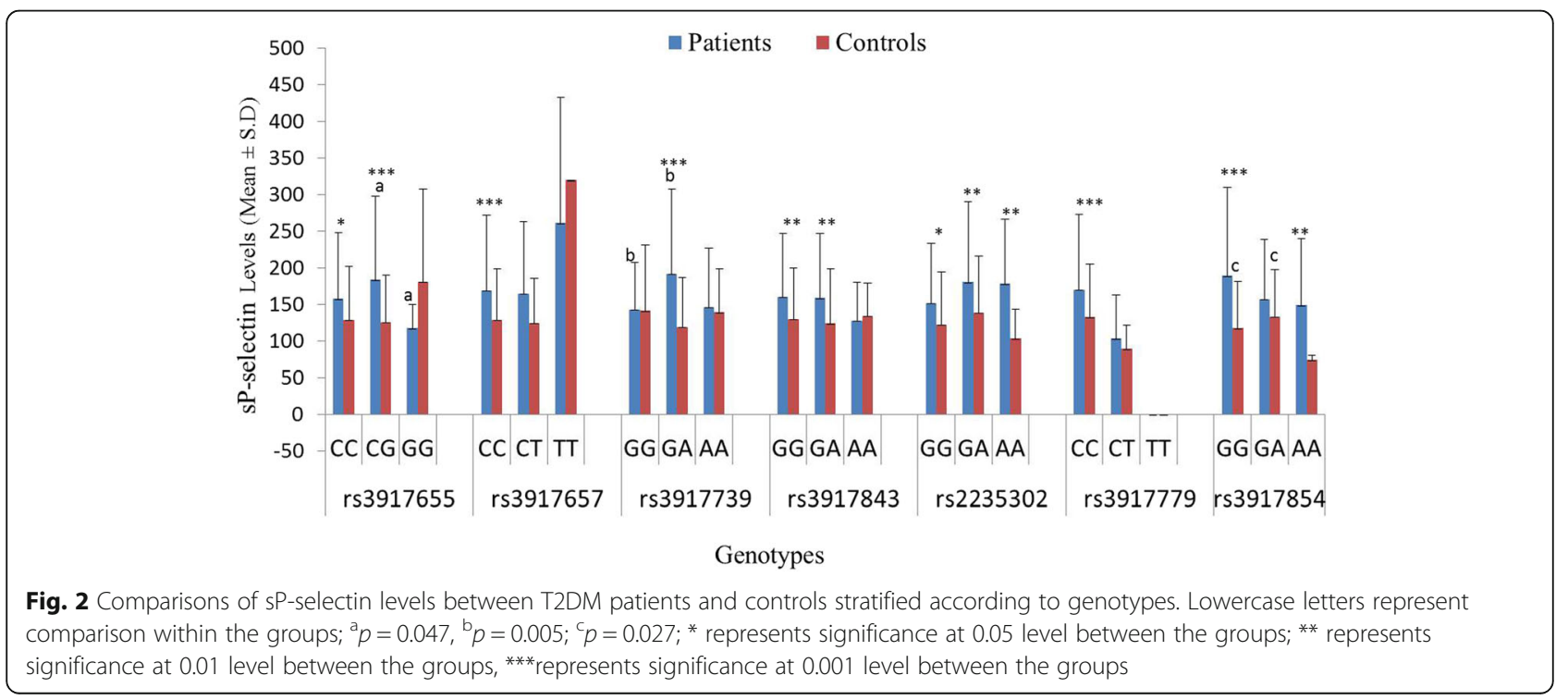




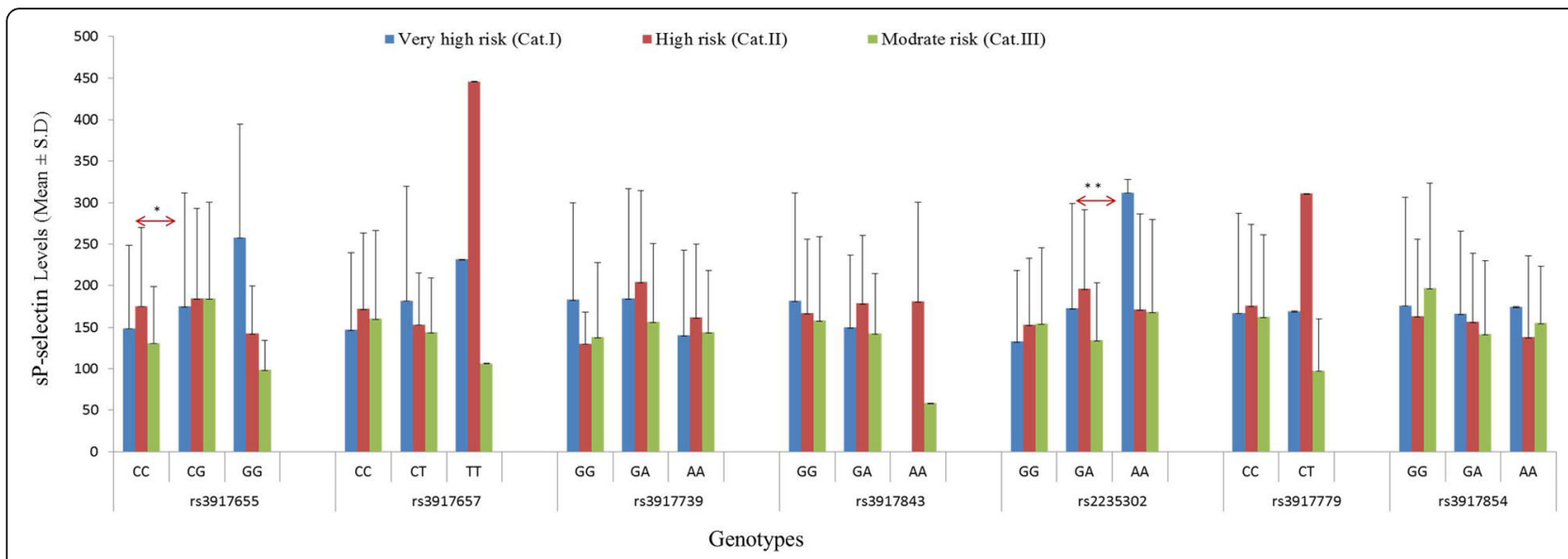

Fig. 3 Comparison of sP-selectin levels between vascular risk categories stratified according to different genotypes. Red arrow represents the comparison between the high risk and moderate risk categories; ${ }^{*}$ represents significance at 0.05 level; ** represents significance at 0.01 level

control setup to evaluate the role of nine putative functional non-coding variants of SELP in modulation of sP-selectin levels and vascular risk in T2DM. As per literature survey, this is the first research report on study of non-coding SNPs of SELP in relation to sP-selectin levels as well as arterial stiffness in T2DM patients in any Asian population.

The clinical relevance of three SNP variants i.e. rs3917655, rs3917853 and rs3917854 has been assessed for first time in the present study. Out of these, only rs3917854 has shown significant association with T2DM as well as vascular risk. Furthermore, both $\mathrm{T}$ and $\mathrm{C}$ allele carriers were observed to have equal odds of T2DM. Out of the other variants, only three variants i.e. rs3917657, rs2235302, rs3917779 were found to be associated with different disease conditions. In a Genome- wide linkage study including UK and USA populations, a stronger association of rs3917657 was observed with SLE [49]. Another important non-coding SNP rs2235302 is located between consensus repeat (CR) 3 and CR4. In the present study, variant allele of rs2235302 was found to be protective. Furthermore, carriers of $\mathrm{G}$ allele have been shown to be associated with equal odds of T2DM as carriers with A allele. However, this variant was shown to be associated with increased thickness of carotid intima media in a previous study [50]. The 3rd important variant i.e. rs3917779 is located in the intron 10 at binding site of transcriptional repressor CTCF (CCCTC-binding factor), known to be involved in various regulatory activities $[65,66]$. It was associated with the development of proliferative diabetic retinopathy in Iranian population [51]. The study suggested that TT

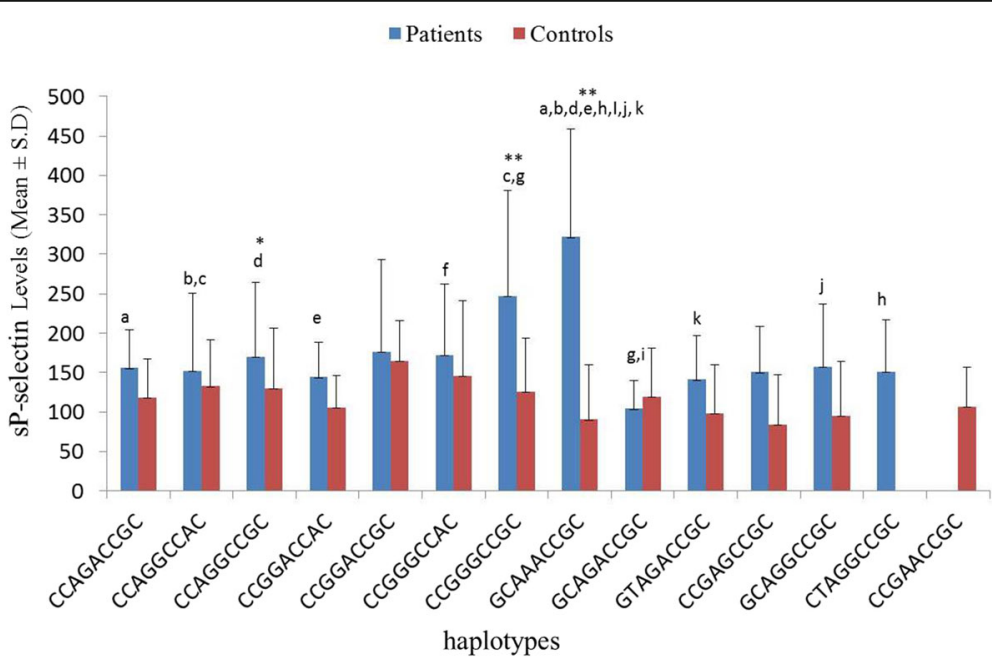

Fig. 4 Comparison of sP-selectin levels between T2DM patients and controls segregated according to haplotypes. ${ }^{\mathrm{a}} p=0.010,{ }^{\mathrm{b}} p=0.004 ;{ }^{\mathrm{cj}} p=$ $0.026,{ }^{d} p=0.017,{ }^{e} p=0.023,{ }^{f} p=0.043,{ }^{9} p=0.032,{ }^{h} p=0.006,{ }^{i} p=0.003,{ }^{k} p=0.007$; ${ }^{*}$ represents significance at 0.05 level between the groups; **represents significance at 0.01 level between the groups 


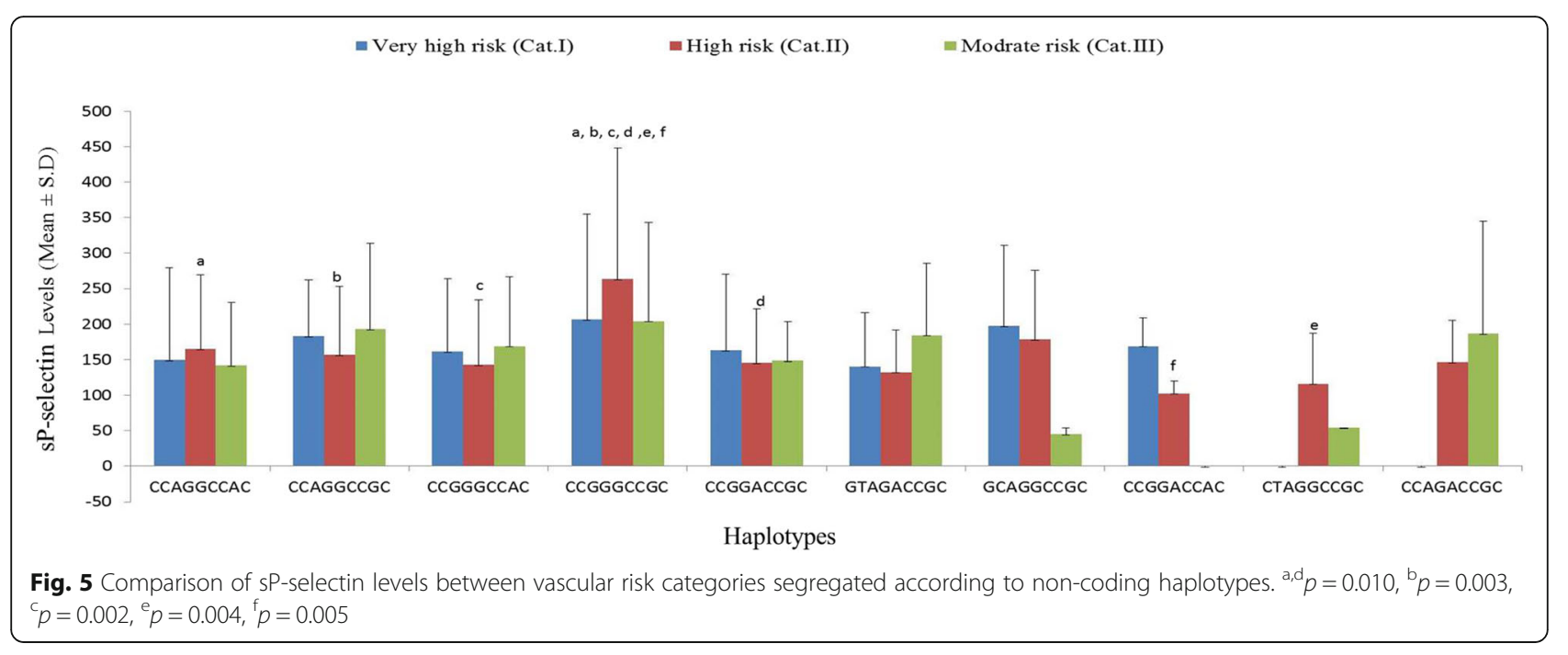

genotype of rs3917779 may abolish CCCTC- binding factor binding site, thus affect the transcription [51]. In the present genetic association study, no variant genotype (TT) was observed in any of the studied group. Furthermore, no statistically significant association was observed with T2DM and vascular risk. In addition, the patterns of pairwise LD displayed by SELP polymorphisms suggested the existence of highly conserved haplotypes.

After performing genotypic analyses of all the studied SNPs, haplotypes were constructed. The haplotype-based approaches have several advantages over the traditional genotype-based strategies [67]. Haplotypes may have specific significance with respect to functionability or as markers for unidentified functional variations. The haplotype-based approach may provide a better tool to distinguish haplotype from a single variant and to determine whether the influence of the variant dependent upon the haplotypic background by which it is carried or not. Moreover, the candidate genes are further translated into polypeptides, which may structurally and functionally dependent on the presence of various amino acids. Thus, for better depiction of role of a candidate gene, the full exploitation of haplotypic information is very important [68, 69]. Only GCAGGCCGC haplotype was observed at significantly high frequency in T2DM patients as compared to controls, conferring 4.1 -fold risk of disease development. In this haplotype, seven out of nine alleles were wild alleles except for rs3917655 (G) and rs3917739 (C). Both of these variants were observed to be in LD with rs3917657, associated with 2 -fold risk of disease development. Evolutionary conservation of rs3917655G and rs3917739C alleles (and its adjoining sequence) provided tentative evidence for their functionality. There are only two reports showing haplotype distribution of SELP variants in T2DM patients $[26,70]$.

Furthermore, no statistically significant difference was obtained in frequencies of non-coding haplotype between the vascular risk categories. Previous studies suggested that various haplotypes of SELP polymorphisms may be established as the predictive marker in the etiology of various diseases including MI, CHD, SLE, venous thromboembolism, recurrent spontaneous abortions $[35,39,40,49,67,71]$. As per literature survey, this is the first comprehensive study involving the genotypic and haplotypic analyses of putative functional noncoding variants of SELP in T2DM as well as vascular risk categories.

A genotypic-phenotypic correlation analyses was also executed for $S E L P$ variants and haplotypes in the studied groups. Association of SELP variants and haplotypes has earlier been assessed with sP-selectin levels in different disease conditions [26, 36, 44-48]. Overall sP-selectin levels were higher in T2DM patients when segregated according to genotypes as well as haplotypes. There are only two reports showing significant association of one non-coding variant (rs2235302) with higher sP-selectin levels $[48,50]$. Significant genotype-phenotype correlations were observed for rs3917655 as well as rs3917739 variant within patients and for rs3917854 within controls.

Furthermore, sP-selectin levels were also segregated according to SELP haplotypes. Patients with GCAAACCGC haplotype, containing variant allele of rs3917655, rs3917739, rs3917843 and rs2235302, were observed with significantly increased levels of sP-selectin than patients with haplotype CCAGACCGC, CCAGGCCAC, CCAGGCCGC, CCGGACCAC, CTAGGCCGC, GCAGACCGC, GCAGGCCGC, GTAGACCGC and controls 
with the GCAAACCGC haplotype. When studied individually, all these four SNPs rs3917655, rs3917739, rs3917843 and rs2235302 were also accounted for high sP-selectin levels in patients than controls. Variant allele of rs3917843, associated with GCAAACCGC haplotype, may account for significantly high level of sP-selectin, because of its absence in other haplotypes. Furthermore, haplotype CCGGGCCGC containing all the wild alleles was also observed with significantly high sP-selectin levels in patients as compared to patients with haplotype CCAGGCCAC and GCAGACCGC and controls with alike haplotypes. This is the first report showing the genotypic and haplotypic association of non-coding SELP polymorphisms in T2DM as well as vascular risk categories.

A question however arises as to what the possible explanation for these SELP variants in risk is as well as protection towards disease development. In silico analyses of the majority of the SNPs investigated in the present study showed their regulatory effect by altering the transcription factor (TF) binding site activity [53]. Furthermore, the SNPs localized in close proximity to promoter can cause significant alterations in TFs binding, downregulating SELP transcription and thus affecting intitial steps of adhesion cascade. In addition, glucose and lipid lowering therapies have been indicated as potential factors modulating CVD risk in T2DM [72, 73]. Further studies are warranted to validate these assumptions.

However, there are some limitations in the present study. Although, the present sample size had a sufficient statistical power i.e. $94 \%$ for performing the genetic analyses, the study was insufficiently powered for the vascular risk categories. Furthermore, baPWV, being an expensive method, could not to be performed in controls. In addition to address these limitations, further studies can be planned to assess contribution of glucose and lipid lowering therapies on CVD risk in T2DM.

\section{Conclusion}

The present study indicated significant modulation of sPselectin levels, vascular risk and T2DM susceptibility, associated with non-coding SELP variants. The findings of this study may provide promising basis for understanding genotype-phenotype correlation in the pathogenesis of complex disease conditions and develop protocols for intervention strategies. In addition, our findings strongly indicate that non-coding polymorphisms of SELP may serve as novel molecular biomarkers for early prediction as well as screening of vascular risk and even as potential therapeutic targets. The outcomes of the present study provide a rationale for extensive screening of SELP variants in the diverse populations.

\section{Supplementary information}

Supplementary information accompanies this paper at https://doi.org/10. 1186/s12902-020-00548-X.

Additional file 1: Figure S1. (a) Representative agarose gel showing PCR product of size $405 \mathrm{bp}$ and restriction digestion products obtained for rs3917655. Figure S2. (a) Representative agarose gel showing PCR product of size $516 \mathrm{bp}$ and restriction digestion products obtained for rs3917657. Figure S4. (a) Representative agarose gel showing PCR product of size $578 \mathrm{bp}$ and restriction digestion products obtained for rs3917843. Figure S5. (a) Representative agarose gel showing PCR product of size $511 \mathrm{bp}$ and restriction digestion products obtained for rs2235302. Figure S6. (a) Representative agarose gel showing ARMS-PCR products of size 441, 254 and 243 bp for rs3917779. Figure S7. (a) Representative agarose gel showing PCR product of size 620 bp obtained after amplification of gene region showing rs3917853, rs3917854 and rs3917855; (b) Electropherograms of representative samples of rs3917853 confirming homozygous wild genotype; (c) Electropherograms of representative samples of rs3917855 confirming homozygous wild genotype; (d)Electropherograms of representative samples of rs3917854 confirming homozygous wild genotype; (e) homozygous variant genotype and (f) heterozygous genotype.

Additional file 2: Table S1. Details of various components used in PCR-RFLP of rs3917655, rs3917657, rs3917739, rs3917843 and rs2235302. Table S2. PCR components and their concentrations used for rs 3917779.

\section{Abbreviations}

ARMS: Amplification-refractory mutation system; baPWV: Brachial-ankle pulse wave velocity; CAD: Coronary artery disease; CHD: Coronary heart disease; CR: Consensus repeat; DNA: Deoxyribonucleic acid;

EDTA: Ethylenediaminetetraacetic acid; EtBr: Ethidium bromide;

ELISA: Enzyme-linked immunosorbent assay; HbA1c: lycated hemoglobin; ICMR: Indian Council of Medical Research guidelines; IDF: International Diabetes Federation; LD: Linkage disequilibrium; MI: Myocardial infarction; PAD: Peripheral artery disease; PB: Punjab; PCR: Polymerase chain reaction; RFLP: Restriction fragment length polymorphism; SNPs: Single-nucleotide polymorphisms; SP-selectin: soluble P-selectin; SPSS: Statistical package for Social science; T2DM: Type 2 diabetes mellitus

\section{Acknowledgements}

The work was supported by financial assistance under INSPIRE fellowship programme (IF-130841) and Promotion of University Research and Scientific Excellence (PURSE) grant by Department of Science and Technology (DST), New Delhi.

\section{Authors' contributions}

All the authors have contributed in conceiving and designing the research work presented in this manuscript. [RK]1 carried out all the biochemical, molecular as well as statistical analysis and drafted the manuscript. JS and MK were closely associated with designing, execution and supervision of the experimental work. Both authors assisted in compiling and drafting, followed by critical reading of the manuscript. [RK]2 was instrumental in recruitment of patients, providing their blood samples, disease history and other relevant information. All authors have read and approved the manuscript in its current state.

\section{Funding}

The work was supported by financial assistance under INSPIRE fellowship programme (IF-130841) and Promotion of University Research and Scientific Excellence (PURSE) grant by Department of Science and Technology (DST), New Delhi.

\section{Availability of data and materials}

The datasets used and/or analyzed during the current study are available from the corresponding author on reasonable request.

\section{Ethics approval and consent to participate}

Written voluntary informed consent was obtained from all the study participants and the study protocol was approved by ethics committee of Guru Nanak Dev University, Amritsar (PB), India, according to Indian Council of Medical Research guidelines (ICMR 2006) adapted from declaration of Helsinki (2004). 


\section{Consent for publication}

Not applicable.

\section{Competing interests}

All the authors state no conflict of interest in the manuscript.

\section{Author details}

${ }^{1}$ School of Medicine, Wayne State University, Detroit, Michigan, USA. ${ }^{2}$ Department of Molecular Biology \& Biochemistry, Guru Nanak Dev University, Amritsar, Punjab, India. ${ }^{3}$ Carewell Heart \& Superspeciality Hospital, Amritsar, Punjab, India.

\section{Received: 8 November 2019 Accepted: 10 May 2020} Published online: 19 May 2020

\section{References}

1. Ogawa H, Nakayama M, Morimoto T, et al. Japanese primary prevention of atherosclerosis with aspirin for diabetes (JPAD) trial investigators. Low-dose aspirin for primary prevention of atherosclerotic events in patients with type 2 diabetes: a randomized controlled trial. JAMA. 2008:300:2134-41.

2. Sarwar N, Gao P, Seshasai SR, et al. Emerging risk factors collaboration. Diabetes mellitus, fasting blood glucose concentration, and risk of vascular disease: a collaborative meta-analysis of 102 prospective studies. Lancet. 2010;375:2215-22.

3. Kochkina MS, Zatěshchikov DA, Sidorenko BA. Measurement of arterial stiffness and its clinical value. Kardiologiia. 2005;45:63-71.

4. Cohn JN, Duprez DA, Grandits GA. Arterial elasticity as part of a comprehensive assessment of cardiovascular risk and drug treatment. Hypertension. 2005;46:217-20.

5. Cruickshank K, Riste L, Anderson SG, Wright JS, Dunn G, Gosling RG. Aortic pulse-wave velocity and its relationship to mortality in diabetes and glucose intolerance: an integrated index of vascular function? Circulation. 2002;106: 2085-90.

6. Saji N, Toba K, Sakurai T. Cerebral small vessel disease and arterial stiffnes: tsunami effect in the brain. Pulse. 2015;3:182-9.

7. Ferreira MT, Leite NC, Cardoso CR, Salles GF. Correlates of aortic stiffness progression in patients with type 2 diabetes: importance of glycemic control: the Rio de Janeiro type 2 diabetes cohort study. Diabetes Care. 2015;38:897-904

8. Di Pino A, Scicali R, Calanna $\mathrm{S}$, et al. Cardiovascular risk profile in subjects with prediabetes and new-onset type 2 diabetes identified by $\mathrm{HbA1C}$ according to American diabetes association criteria. Diabetes Care. 2014;37: 1447-53.

9. Di Pino A, Urbano F, Scicali R, et al. 1 h Postload Glycemia is associated with low endogenous secretory receptor for advanced Glycation end product levels and early markers of cardiovascular disease. Cells. 2019;8:910.

10. Di Pino A, Currenti W, Urbano F, et al. High intake of dietary advanced glycation end-products is associated with increased arterial stiffness and inflammation in subjects with type 2 diabetes. Nutr Metab Cardiovasc Dis. 2017;27:978-84

11. Lehmann ED. Clinical value of aortic pulse-wave velocity measurement. Lancet. 1999;354:528-9.

12. Kim JH, Rhee MY, Kim YS, et al. Brachial-ankle pulse wave velocity for the prediction of the presence and severity of coronary artery disease. Clin Exp Hypertens. 2014;36:404-9.

13. Nakamura M, Yamashita Y, Yajima J, et al. Brachial-ankle pulse wave velocity as a risk stratification index for short term prognosis of type 2 diabetic patients with coronary artery disease. Hypertens Res. 2010;33:1018-24.

14. Nagai K, Shibata S, Akishita M, et al. Efficacy of combined use of three noninvasive atherosclerosis tests to predict vascular events in the elderly; carotid intima-media thickness, flow mediated dilation of brachial artery and pulse wave velocity. Atherosclerosis. 2013;231:365-70.

15. Yiu KH, Zhao CT, Chen Y, et al. Association of subclinical myocardial injury with arterial stiffness in patients with type 2 diabetes mellitus. Cardiovasc Diabetol. 2013;12:94

16. Han JY, Choi DH, Choi SW, et al. Predictive value of brachial-ankle pulse wave velocity for cardiovascular events. AJMS. 2013:346:92-7.

17. Yamashina A, Tomiyama H, Takeda K, et al. Validity, reproducibility, and clinical significance of noninvasive brachial-ankle pulse wave velocity measurement. Hypertens Res. 2002;25:359-64.
18. Blankenberg S, Barbaux S, Tiret L. Adhesion molecules and atherosclerosis. Atherosclerosis. 2002;170:191-203.

19. Laurent $S$, Boutouyrie $P$, Lacolley P. Structural and genetic bases of arterial stiffness. Hypertension. 2005:45:1050-5.

20. Beckman JA, Creager MA, Libby P. Diabetes and atherosclerosis: epidemiology, pathophysiologyand management. JAMA. 2002;287:2570-81.

21. Blann AD, Nadar SK, Lip GY. The adhesion molecule P-selectin and cardiovascular disease. Eur Heart J. 2003:24:2166-79.

22. Huo Y, Xia L. P-selectin glycoprotein ligand-1 plays a crucial role in the selective recruitment of leukocytes into the atherosclerotic arterial wall. Trends Cardiovasc Med. 2009;19:140-5.

23. Ushiyama S, Laue TM, Moore KL, Erickson HP, McEver RP. Structural and functional characterization of monomeric soluble P-selectin and comparison with membrane P-selectin. J Biol Chem. 1993;268:15229-37.

24. Barac A, Campia U, Panza JA. Methods for evaluating endothelial function in humans. Hypertension. 2007:49:748-60

25. Pawelczyk M, Kaczorowska B, Baj Z. The impact of hyperglycemia and hyperlipidemia on plasma P-selectin and platelet markers after ischemic stroke. Arch Med Sci. 2017;13:1049-56.

26. Kaur R, Singh J, Kapoor R, Kaur M. Association of SELP polymorphisms with soluble P-selectin levels and vascular risk in patients with Type 2 diabetes mellitus: A case-control study. Biochem Genet. 2018. https://doi.org/10. 1007/s10528-018-9881-6.

27. Kaur R, Kaur M, Singh J. Endothelial dysfunction and platelet hyperactivity in type 2 diabetes mellitus: molecular insights and therapeutic strategies. Cardiovasc Diabetol. 2018;17:121.

28. Hillis GS, Terregino C, Taggart P, Killian A, Zhao N, et al. Elevated soluble P-selectin levels are associated with an increased risk of early adverse events in patients with presumed myocardial ischemia. Am Heart J. 2002;143:235-41.

29. Lim HS, Blann AD, Lip GYH. Soluble CD40 ligand, soluble P-selectin, interleukin-6, and tissue factor in diabetes mellitus relationships to cardiovascular disease and risk factor intervention. Circulation. 2004;109: 2524-8.

30. Aref S, Sakrana M, Hafez AA, Hamdy M. Soluble P-selectin levels in diabetes mellitus patients with coronary artery disease. Hematology. 2005;10:183-7.

31. Gokulakrishnan K, Deepa R, Mohan V, Gross MD. Soluble P-selectin and CD40L levels in subjects with prediabetes, diabetes mellitus, and metabolic syndrome - the Chennai urban rural epidemiology study. Metabolism. 2006; 55:237-42.

32. Bielinski SJ, Berard C, Decker PA, Kirsch PS, Larson NB, et al. P-selectin and subclinical and clinical atherosclerosis: the multi-ethnic study of atherosclerosis (MESA). Atherosclerosis. 2015;240:3-9.

33. Manka D, Collins RG, Ley K, Beaud AL, Sarembock IJ. Absence of p-selectin, but not intercellular adhesion molecule-1, attenuates neointimal growth after arterial injury in Apolipoprotein e-deficient mice. Circulation. 2001;103: 1000-5.

34. Kee F, Morrison C, Evans AE, McCrum E, McMaster D, Dallongeville J, et al. Polymorphisms of the P-selectin gene and risk of myocardial infarction in men and women in the ECTIM extension study. Etude cas-temoin de I_ infarctus myocarde. Heart. 2000;84:548-52.

35. Tregouet DA, Barbaux S, Escolano S, Tahri N, Golmard JL, Tiret L, et al. Specific haplotypes of the P-selectin gene are associated with myocardial infarction. Hum Mol Genet. 2002;11:2015-23.

36. Barbaux SC, Blankenberg S, Rupprecht HJ, Francomme C, Bickel C, Hafner G, et al. Association between P-selectin gene polymorphisms and soluble Pselectin levels and their relation to coronary artery disease. Arterioscler Thromb Vasc Biol. 2001;21:1668-73.

37. Bourgain C, Hoffjan S, Nicolae R, Newman D, Steiner L, Walker K, et al. Novel case-control test in a founder population identifies P-selectin as an atopysusceptibility locus. Am J Hum Genet. 2003;73:612-26.

38. Zee RY, Cook NR, Cheng S, Reynolds R, Erlich HA, Lindpaintner K, et al. Polymorphism in the P-selectin and interleukin-4 genes as determinants of stroke: a population-based, prospective genetic analysis. Hum Mol Genet. 2004:13:389-96.

39. Volcik KA, Ballantyne CM, Coresh J, Folsom AR, Boerwinkle E. Specific Pselectin and Pselectin glycoprotein ligand-1 genotypes/haplotypes are associated with risk of incident CHD and ischemic stroke: the atherosclerosis risk in communities (ARIC) study. Atherosclerosis. 2007;195: $76-82$.

40. Ay C, Jungbauer LV, Sailer T, Tengler $T$, Koder $\mathrm{S}$, Kaider A, et al. High concentrations of soluble P-selectin are associated with risk of venous 
thromboembolism and the P-selectin Thr715 variant. Clin Chem. 2007;53: 1235-43.

41. Penman A, Hoadley S, Wilson JG, Taylor HA, Chen CJ, Sobrin L. P-selectin plasma levels and genetic variant associated with diabetic retinopathy in African Americans. Am J Ophthalmol. 2015;159:1152-60.

42. Zhu H, Yan W, Tan Y, Li K, Kapuku G, Treiber FA, et al. Adhesion molecule polymorphisms and pulse wave velocity in American youth. Twin Res Hum Genet. 2008;11:517-23.

43. Carter AM, Anagnostopoulou K, Mansfield MW, Grant PJ. Soluble P-selectin levels, P-selectin polymorphisms and cardiovascular disease. J Thromb Haemost. 2003;1:1718-23.

44. Miller MA, Kerry SM, Dong Y, Strazzullo P, Cappuccio FP. Association between the Thr715Pro P-selectin gene polymorphism and soluble Pselectin levels in a multiethnic population in South London. Thromb Haemost. 2004:92:1060-5.

45. Volcik KA, Ballantyne CM, Coresh J, Folsom AR, Wu KK, Boerwinkle E. Pselectin Thr715Pro polymorphism predicts P-selectin levels but not risk of incident coronary heart disease or ischemic stroke in a cohort of 14595 participants: the atherosclerosis risk in communities study. Atherosclerosis. 2006; 186:74-9.

46. Lee DS, Larson MG, Lunetta KL, et al. Clinical and genetic correlates of soluble P-selectin in the community. J Thromb Haemost. 2008;6:20-31.

47. Marteau JB, Lambert D, Herbeth B, Marie B, Droesc S, Tregouet DA, VISVIKISSIEST S. P-selectin polymorphisms' influences on P-selectin serum concentrations and on their familial correlation: the STANISLAS family study. J Thromb Haemost. 2008;6:920-7.

48. Barbalic M, Dupuis J, Dehghan A. Large-scale genomic studies reveal central role of ABO in sP-selectin and sICAM-1 levels. Hum Mol Genet. 2010;19: 1863-72.

49. Morris DL, Graham RR, Erwig LP, et al. Variation in the upstream region of PSelectin (SELP) is a risk factor for SLE. Genes Immun. 2009;10:404-13.

50. Reiner AP, Carlson CS, Thyagarajan B, et al. Soluble P-Selectin, SELP polymorphisms, and atherosclerotic risk in European-American and AfricanAfrican young adults. Arterioscler Thromb Vasc Biol. 2008;28:1549-55.

51. Kolahdouz P, Farashahi YE, Tajamolian M, Manaviat MR, Sheikhha MH. The rs3917779 polymorphism of P-selectin's significant association with proliferative diabetic retinopathy in Yazd, Iran. Graefes Arch Clin Exp Ophthalmol. 2015;253:1967-72.

52. Prokunina L, Riquelme MEA. Regulatory SNPs in complex diseases: their identification and functional validation. Expert Rev Mol Med. 2004:6:1-15.

53. Kaur R, Singh J, Kaur M. Structural and functional impact of SNPs in P-selectin gene: a comprehensive in silico analysis. Open Life Sci. 2017;12:19-33.

54. Kaur R, Kaur M, Kapoor R, Singh J. Assessment of metabolic syndrome and clinical significance of brachial-ankle pulse wave velocity in type 2 diabetes mellitus patients. Rom J Diabet Nutr Metab Dis. 2017;24:213-26.

55. Atlas ID. International Diabetes Federation. 6th ed. Brussels; 2013. URL: https://www.idf.org/e-library/epidemiology-research/diabetes-atlas/19-atlas6th edition.html. Accessed 10 July 2017.

56. Stephens M, Smith NJ, Donnelly P. A new statistical method for haplotype reconstruction from population data. Am J Hum Genet. 2001;68:978-89.

57. Barrett JC, Gaida MM, Kahle N, Schuppel AK, Kathrey D, Prior B, et al. Haploview: analysis and visualization of $L D$ and haplotype maps. Bioinformatics. 2005;21:263-5.

58. Behnam-Rassouli M, Ghayour MB, Ghayour N. Microvascular complications of diabetes. J Biol Sci. 2010;10:411-23.

59. Haffner SM, Lehto S, Rönnemaa T, Pyörälä K, Laakso M. Mortality from coronary heart disease in subjects with type 2 diabetes and in nondiabetic subjects with and without prior myocardial infarction. N Engl J Med. 1998; 339:229-34.

60. Beckman JA, Creager MA, Libby P. Diabetes and atherosclerosis: epidemiology, pathophysiology, and management. JAMA. 2002;287: 2570-81.

61. Creager MA, Lüscher TF, Cosentino F, Beckman JA. Diabetes and vascular disease: pathophysiology, clinical consequences, and medical therapy: part I. Circulation. 2003;108:1527-32.

62. Nesto RW. Correlation between cardiovascular disease and diabetes mellitus: current concepts. Am J Med. 2004;116:11-22.

63. Elmas E, Bugert P, Popp T, et al. The P-Selectin gene polymorphism Val168Met: a novel risk marker for the occurrence of primary ventricular fibrillation during acute myocardial infarction. J Cardiovasc Electrophysiol. 2010;21:1260-5.
64. Sivapalaratnam S, Motazacker MM, Maiwald S, et al. Genome-wide association studies in atherosclerosis. Curr Atheroscler Rep. 2011:13:225-32.

65. Phillips JE, Corces VG. CTCF: master weaver of the genome. Cell. 2009;137: 1194-211.

66. Shukla S, Kavak E, Gregory M, et al. CTCF-promoted RNA polymerase II pausing links DNA methylation to splicing. Nature. 2011:479:74.

67. Herrmann SM, Ricard S, Nicaud V, et al. The P-selectin gene is highly polymorphic: reduced frequency of the Pro715 allele carriers in patients with myocardial infarction. Hum Mol Genet. 1998;7:1277-84.

68. Hodge SE, Boehnke M, Spence MA. Loss of information due to ambiguous haplotyping of SNPs. Nat Genet. 1999:21:360.

69. Rieder MJ, Taylor SL, Clark AG, Nickerson DA. Sequence variation in the human angiotensin converting enzyme. Nat Genet. 1999;22:59-62.

70. Zalewski G, Ciccarone E, Di Castelnuovo A, et al. P-selectin gene genotypes or haplotypes and cardiovascular complications in type 2 diabetes mellitus. Nutr Metab Cardiovasc Dis. 2006;16:418-25.

71. Dendana M, Hizem S, Magddoud K, et al. Common polymorphisms in the P-selectin gene in women with recurrent spontaneous abortions. Gene. 2012:495:72-5.

72. Scicali R, Di Pino A, Ferrara V. New treatment options for lipid-lowering therapy in subjects with type 2 diabetes. Acta diabetologica. 2018;55:20918.

73. Buse JB, Wexler DJ, Tsapas A, et al. 2019 update to: management of hyperglycemia in type 2 diabetes, 2018. A consensus report by the American Diabetes Association (ADA) and the European Association for the Study of Diabetes (EASD). Diabetes Care. 2020;43:487-93.

\section{Publisher's Note}

Springer Nature remains neutral with regard to jurisdictional claims in published maps and institutional affiliations.

Ready to submit your research? Choose BMC and benefit from:

- fast, convenient online submission

- thorough peer review by experienced researchers in your field

- rapid publication on acceptance

- support for research data, including large and complex data types

- gold Open Access which fosters wider collaboration and increased citations

- maximum visibility for your research: over $100 \mathrm{M}$ website views per year

At BMC, research is always in progress.

Learn more biomedcentral.com/submissions 